\title{
Reação do Mercado à Alteração na Composição da Carteira de Índices de Bolsa de Valores Brasileiros
}

\author{
Jairo Laser Procianoy* \\ Rodrigo S. Verdi**
}

\section{Resumo}

Este artigo analisa o comportamento do preço e do volume das negociações de ações adicionadas e excluídas do IBOVESPA, do IBrX50, do IBrX100 durante o período de 1994 a 2002 e do FGV100 durante o período de 2000 a 2002. Não encontrou-se evidência de retornos anormais em torno da prévia das alterações do IBOVESPA em contraste com resultados obtidos nos Estados Unidos. A análise de retornos anormais em torno da data da efetiva alteração da carteira dos índices sugere uma reação positiva em torno da efetiva alteração do IBOVESPA e do IBrX50 mas esse efeito torna-se negativo ao final da janela do evento de cinco dias. Já no caso das exclusões, em todos os casos constatou-se evidência de retornos anormais cumulativos negativos ao final de cinco dias após a efetiva alteração das carteiras. Finalmente, constata-se a existência de volumes anormais nos dias anteriores a alteração da carteira para ações adicionadas e excluídas ao IBOVESPA.

Palavras-chave: pressão nos preços das ações; Ibovespa; S\&P 500

Códigos JEL: G00; G1; G14.

\section{Abstract}

This study investigates the price and volume behavior of stock added and excluded to the IBOVESPA, IBrX50, and IBrX100 indexes during the years 1994 to 2002 and FGV100 index during the years 2000 to 2002. In contrast to findings in the US, we find no evidence of abnormal returns around the announcement of changes in the IBOVESPA. We find shortterm positive abnormal return to stocks added to the IBOVESPA and IBrX50. There is evidence of negative cumulative returns for stocks excluded from the indexes. We also find positive abnormal trade volume on the date before the stocks were added to the IBOVESPA index.

Keywords: price pressure; index changes; IBOVESPA; S\&P 500.

Submetido em Abril de 2006. Revisado em Dezembro de 2006. Os autores agradecem o suporte financeiro do CNPq (Procianoy) e da Wharton School e da MIT Sloan School of Management (Verdi). Além disso, reconhece-se o excelente trabalho de suporte de pesquisa de Felipe Abrantes na coleta dos dados e das informações necessárias.

*PPGA/EA/UFRGS. Av. Carlos Gomes 1111 apto 1201, Porto Alegre - RS - Brasil -90.480-004, Tel (51) 3331-4693. E-mail: jlprocianoy@ea.ufrgs.br

**Sloan School of Management. Massachusetts Institute of Technology, 50 Memorial Drive E52403A, Cambridge, MA 02142. E-mail: rverdi@mit.edu 


\section{Introdução}

Este artigo analisa o comportamento do preço e do volume das negociações de ações adicionadas e excluídas ao IBOVESPA, ao IBrX50 e ao IBrX100 durante os anos 1994 a 2002 e ao índice FGV100 durante os anos 2000 a 2002. ${ }^{1}$ Diversos estudos nos Estados Unidos tentam explicar a reação do mercado a alterações no índice S\&P 500. No entanto, não existe muita evidência do efeito nos preços das ações adicionadas e excluídas nos índices brasileiros. Uma única exceção é o estudo de Salazar (1997) que examinou as adições e exclusões no IBOVESPA entre 02 de janeiro de 1990 e 03 de janeiro de 1995, tendo encontrado que as inclusões afetam favoravelmente o preço da respectiva ação e a exclusão representam más noticias aos investidores com a respectiva queda do preço da ação em questão.

Diversas teorias tentam explicar o efeito no preço das ações adicionadas ou excluídas aos índices financeiros. ${ }^{2}$ Tradicionalmente, a teoria financeira assume que os investidores podem comprar e vender ações em grandes quantidades sem afetar seus preços (Modigliani e Miller, 1958). Neste caso, um aumento de demanda por uma ação não deveria afetar o preço desta ação. Por outro lado, o anúncio de inclusão ou exclusão de uma ação a um índice financeiro pode afetar o preço da ação caso o anúncio afete a percepção dos investidores em relação ao fluxo de caixa esperado ou ao custo de capital (Jain, 1987, Dhillon e Johnson, 1991, Denis et alii, 2003, Hegde e McDermott, 2003). Finalmente, alguns estudos questionam o pressuposto de que a demanda das ações em relação ao preço é perfeitamente elástica. Neste caso, a explicação para o movimento no preço das ações deve-se ao fato de que a curva de demanda é decrescente e, portanto o preço da ação é afetado por uma demanda anormal pelo ativo (Goetzmann e Garry, 1986, Harris e Eitan, 1986, Shleifer, 1986).

Uma implicação das teorias acima é que a efetiva data da alteração da carteira teórica dos índices não deveria afetar o preço da ação se o anúncio das alterações nas carteiras seja previamente realizado (Shleifer, 1986). Neste caso qualquer efeito informacional desta alteração já deveria ter sido assimilado pelo mercado em momento anterior. Por outro lado, a data da efetiva alteração na carteira teórica dos índices representa um período de alta (baixa) demanda pelos papéis adicionados (excluídos) aos índices uma vez que vários fundos de investimentos caracterizamse por uma administração "passiva" que tem como objetivo replicar a rentabilidade de um determinado índice no respectivo fundo. Dessa forma, ações adicionadas, ou excluídas, dos fundos sofrem uma alteração de demanda temporária no período em torno das alterações da composição dos índices em consequiência dos ajustes das carteiras de fundos replicadores de índices. Portanto, se a elasticidade da demanda pela ação não for perfeitamente elástica, é possivel a existência de retornos anormais em torno da efetiva da de alteração da composição das carteiras dos índices em função do aumento de demanada de fundos indexadores.

\footnotetext{
${ }^{1}$ Utilizamos alterações no índice FGV100 a partir do ano 2000 porque não obtivemos informações das datas das alterações da composição do índice FGV100 para os anos anteriores.

${ }^{2}$ A Seção 2 sumariza essas teorias em maior detalhe.
} 
Um fator diferenciador desse estudo no mercado brasileiro é que a Bolsa de Valores de São Paulo - BOVESPA apresenta a prévia da alteração do IBOVESPA com 30 dias de antecedência da data efetiva. Isso permite separar o efeito informacional do efeito de liquidez devido a ajustes de carteiras dos fundos indexadores. Nos Estados Unidos, essa distinção tornou-se possível apenas após outubro de 1989 quando a Standard and Poor's passou a anunciar previamente a alteração da carteira do S\&P 500. Além disso, a BOVESPA estabelece critérios definidos pra alterações na carteira do IBOVESPA. Neste caso é possível que os investidores antecipem a alteração da carteira e a data da prévia não tenha valor informacional.

Nesse estudo realizou-se uma análise sistemática de retornos e volumes anormais em torno da data de alteração de vários índices financeiros brasileiros. Além disso, realizou-se uma análise de retornos anormais em torno da data da prévia da alteração do IBOVESPA. Os resultados sugerem que não existe evidência de retornos anormais em torno da data da prévia das alterações do índice IBOVESPA em contraste com resultados obtidos nos Estados Unidos. Uma possível explicação para o fato é que, devido a BOVESPA adotar critérios definidos para a inclusão e exclusão de uma companhia na carteira, é possível que os investidores antecipem a alteração da composição do índice IBOVESPA o que torna a data da prévia da BOVESPA não informativa.

A análise de retornos anormais em torno da data da efetiva alteração da carteira dos índices nos permite chegar às seguintes conclusões: i) encontrou-se uma reação positiva em torno da efetiva alteração dos índices IBOVESPA e IBrX50 (dias “-2", "-1" e "0") mas esse efeito torna-se negativo ao final da janela do evento de cinco dias; ii) o único caso de retornos anormais cumulativos positivos ao final da janela do evento (i.e., cinco dias após o evento) foi em torno das empresas adicionadas ao índice FGV100, porém esse resultado não é significativo estatisticamente; iii) para as exclusões, em todos os casos constatou-se evidência de retornos anormais cumulativos negativos ao final de cinco dias após a efetiva alteração das carteiras. No entanto, observou-se significância estatística apenas para exclusões ao IBOVESPA e ao IBrX100. ${ }^{3}$

Finalmente, constata-se a existência de volumes anormais nos dias anteriores a alteração da carteira para ações adicionadas e excluídas ao índice IBOVESPA. Os resultados podem ser interpretados como um ajuste na composição da carteira de fundos de investimentos que tem como objetivo replicar a rentabilidade do índice IBOVESPA.

Este artigo contribui para essa literatura da seguinte forma: Primeiramente, esse estudo realiza uma análise sistemática de retornos e volumes anormais em torno da data de anúncio e alteração de vários índices financeiros brasileiros. Segundo, a ausência de retornos anormais em torno da prévia da alteração do IBO-

${ }^{3}$ Além disso, analisamos 28 (13) eventos de empresas que entraram (saíram) em dois ou mais índices na mesma data. Para as empresas adicionadas (excluídas) ao índice, os resultados sugerem um retorno anormal de $2.3 \%(-3.8 \%)$ na data do evento. No entanto, os retornos anormais cumulativos para as empresas adicionadas aos índices tornam-se negativos ao final da janela do evento. 
VESPA contrasta com resultados encontrados utilizando adições e exclusões no S\&P 500. Esse resultado sugere que investidores brasileiros possam antecipar a alteração da composição dos índices uma vez que os critérios de alteração na carteira do IBOVESPA são previamente estabelecidos. Finalmente, a evidência de retornos anormais temporários em torno das empresas adicionadas aos índices brasileiros sugere que a elasticidade da demanda em relação ao preço no mercado brasileiro não é perfeita. Esse resultado é consistente com os resultados em Harris e Eitan (1986) e Shleifer (1986).

A próxima seção apresenta uma revisão da literatura e a Seção 3 discute a metodologia utilizada. A Seção 4 descreve a seleção e as características da amostra. Os resultados são apresentados na Seção 5 e a última parte sintetiza as conclusões do estudo.

\section{Revisão da Literatura}

Diversas teorias tentam explicar o efeito no preço das ações adicionadas ou excluídas à índices financeiros. Em geral essas teorias buscam verificar o movimento do mercado em torno do anúncio da alteração da carteira dos índices (essa data é conhecida na literatura como announcement date). Outras teorias explicam a reação do mercado na data da efetiva alteração da composição dos índices (essa data é conhecida na literatura como effective date). Esta seção sumariza essas diversas teorias.

Tradicionalmente, a teoria financeira assume que os investidores podem comprar e vender ações em grandes quantidades sem afetar o preço. Isto é, a teoria assume que as ações no mercado de capitais tem demanda perfeitamente elástica em relação ao preço. Por exemplo, esse pressuposto é utilizado no famoso teorema de Modigliani e Miller (1958). Segundo essa teoria, o anúncio da entrada de uma ação ao índice financeiro não deveria ter nenhum efeito no preço da respectiva ação se a única mudança que ocorre no ativo for um aumento de demanda.

No entanto, mesmo com o pressuposto de que a demanda é perfeitamente elástica, alguns autores mostram que o anúncio de inclusão de uma ação ao índice financeiro pode afetar o preço da ação caso o anúncio afete a percepção dos investidores em relação ao fluxo de caixa esperado ou ao custo de capital. Por exemplo, empresas adicionadas ao índice podem alterar o fluxo de caixa esperado devido ao aumento da exposição aos consumidores (Jain, 1987, Dhillon e Johnson, 1991) e ao aumento de monitoração por parte dos investidores e participantes dos mercados financeiros (Denis et alii, 2003). Da mesma forma, empresas adicionadas aos índices podem alterar o custo de capital devido ao aumento de liquidez da ação (Chordia, 2001, Hegde e McDermott, 2003) e ao aumento da base de investidores (Merton, 1987). Portanto, esses estudos proporcionam uma explicação racional para um aumento (decréscimo) permanente no preço de ações adicionadas (excluídas) aos índices financeiros. 
Outros estudos questionam o pressuposto de que a demanda das ações é perfeitamente elástica. Neste caso, a explicação para o movimento no preço das ações deve-se ao fato de que a curva de demanda é decrescente e, portanto o preço da ação é afetado por uma demanda anormal pelo ativo. No entanto, esses estudos divergem no que diz respeito à duração do efeito da nova informação no preço do ativo. Isto é, alguns artigos sugerem que o efeito é de curto prazo (Harris e Eitan, 1986, Blouin et alii, 2000) e outros documentam efeitos de longo prazo (Goetzmann e Garry, 1986, Shleifer, 1986, Beneish e Whaley, 1996, Lynch e Mendenhall, 1997, Kaul et alii, 2000). Mais recentemente Chen et alii (2004) documentam que a adição de um ação ao índice $\mathrm{S} \& \mathrm{P} 500$ tem um efeito permanente no preço da ação mas que a exclusão tem um efeito temporário. Esses autores concluem que a evidência empírica pode ser explicada pelo fato de que quando uma empresa é adicionada a um índice financeiro, essa empresa passa a ser mais conhecida pelos investidores, o que causa um efeito permanente. Por outro lado, quando uma empresa é excluída de um índice, os investidores continuam conhecendo a empresa e qualquer efeito no preço da ação tem caráter temporário.

Um fator importante nos estudos que avaliam o impacto da adição de uma empresa a um índice financeiro é a distinção entre a data do anúncio e a data da efetiva alteração da composição deste índice. Essa distinção é importante porque qualquer efeito informacional deveria afetar o preço da ação na data do anúncio. Por outro lado, diversos fundos de investimento têm como objetivo replicar a rentabilidade dos índices financeiros e esses fundos, mesmo sabendo previamente da alteração da carteira, não ajustam a carteira de investimentos até a data da efetiva alteração. Portanto, é possível que o efeito ocorra em dois períodos: um efeito na data do anúncio e um efeito na data da alteração da carteira. Porém, qualquer efeito na data da efetiva alteração deveria ser temporário refletindo apenas a variação na demanda pelo ativo por parte de fundos indexadores. Shleifer (1986) discute essa teoria em maior detalhe.

\subsection{Comparação entre o S\&P 500 e os índices brasileiros}

O índice S\&P 500 alterou duas vezes a política de anuncio da alteração de sua carteira. Durante julho de 1962 até agosto de 1976 não havia anúncio publico da alteração da composição da carteira do índice S\&P 500. A partir de setembro de 1976 até setembro de 1989, a Standard and Poor's passou a anunciar publicamente a alteração do S\&P 500. As alterações das carteiras eram anunciadas no final da tarde quando o mercado já havia fechado e a nova composição do índice entrava em vigor no dia seguinte. Portanto não havia distinção entre a data do anúncio e a data da efetiva alteração dado que os dois eventos aconteciam no mesmo dia de negociação. Finalmente, a partir de outubro de 1989, a Standard and Poor's passou a anunciar previamente a alteração da carteira do S\&P 500. O anúncio continuou sendo publicado após o encerramento do mercado, mas a data efetiva ocorre em até 30 dias após a data do anúncio. 
Em relação aos índices brasileiros, o que mais se parece com o processo mais recente do S\&P 500 é o IBOVESPA. Para o IBOVESPA, a BOVESPA oferece prévias da composição do índice com 30, 15 e 1 dia de antecedência à data efetiva. ${ }^{4}$ Por outro lado, a BOVESPA não esclarece procedimentos de anúncios das alterações do IBrX50 e do IBrX100. Da mesma forma, a Fundação Getulio Vargas não pré-anuncia as alterações na composição do índice FGV100. Dessa forma, o processo de alteração do IBrX50, do IBrX100 e do índice FGV100 são mais semelhantes ao processo de alteração no S\&P 500 durante os anos de 1976 a 1989 com a alteração e a efetivação da modificação no índice ocorrendo na mesma data.

\subsection{Descrição dos índices}

O IBOVESPA é o mais importante indicador do desempenho médio das cotações do mercado de ações brasileiro. Sua relevância advém do fato dele retratar o comportamento dos principais papéis negociados na BOVESPA e também de sua tradição por manter a integridade de sua série histórica ao longo dos anos. É o valor atual, em moeda corrente, de uma carteira teórica de ações constituída em 02/01/1968, a partir de uma aplicação hipotética. ${ }^{5}$ Supõe-se não ter sido efetuado nenhum investimento adicional desde então, considerando-se somente os ajustes efetuados em decorrência da distribuição de proventos pelas empresas emissoras (tais como reinversão de dividendos recebidos e do valor apurado com a venda de direitos de subscrição, e manutenção em carteira das ações recebidas em bonificação). Dessa forma, o índice reflete não apenas as variações dos preços das ações, mas também o impacto da distribuição dos proventos, sendo considerado um indicador que avalia o retorno total de suas ações componentes.

As ações integrantes da carteira teórica do índice IBOVESPA respondem por mais de $80 \%$ do número de negócios e do volume financeiro verificado no mercado à vista (lote-padrão) da BOVESPA. As empresas emissoras das ações integrantes da carteira teórica do índice IBOVESPA são responsáveis, em média, por aproximadamente $70 \%$ do somatório da capitalização bursátil de todas as empresas com ações negociáveis na BOVESPA. Ele é calculado em tempo real considerando os preços dos últimos negócios efetuados no mercado à vista (lote-padrão) com ações componentes de sua carteira. Sua divulgação é feita pela rede de difusão da BOVESPA e também retransmitida por uma série de "vendors", sendo possível, dessa forma, acompanhar "on line" seu comportamento em qualquer parte do Brasil ou do mundo. Prévias das modificações são divulgadas mensalmente como forma do mercado ter uma previsão das modificações que estão ocorrendo na liquidez das diferentes ações e como será, se for o caso, modificado o índice. ${ }^{6}$

O IBrX100, ou simplesmente IBrX, é um índice de preços que mede o retorno de uma carteira teórica composta por 100 ações selecionadas entre as mais ne-

\footnotetext{
${ }^{4}$ Para maiores detalhes consultar www.bovespa.com.br/Pdf/Indices/Ibovespa.pdf, p.8.

${ }^{5}$ O IBOVESPA sofreu adequações em função da inflação quando foram retirados zeros para refletir a nova realidade nos seus diversos momentos.

${ }^{6}$ Para maiores detalhes consultar www.bovespa.com.br/Pdf/Indices/IBovespa.pdf.
} 
gociadas na BOVESPA, em termos de número de negócios e volume financeiro. Essas ações são ponderadas na carteira do índice pelo seu respectivo número de ações disponíveis à negociação no mercado. Para fazerem parte do índice as ações devem estar entre as 100 melhores classificadas quanto ao seu índice de negociabilidade, apurados nos doze meses anteriores à reavaliação e terem sido negociadas em pelo menos $70 \%$ dos pregões ocorridos nos doze meses anteriores à formação da carteira. Uma ação será excluída do índice, nas reavaliações periódicas, quando deixar de atender aos critérios de inclusão. ${ }^{7}$

O IBrX50 é um índice que mede o retorno total de uma carteira teórica composta por 50 ações selecionadas entre as mais negociadas na BOVESPA em termos de liquidez, ponderadas na carteira pelo valor de mercado das ações disponíveis à negociação. Ele foi desenhado para ser um referencial para os investidores e administradores de carteira, e também para possibilitar o lançamento de derivativos (futuros, opções sobre futuro e opções sobre índice). O IBrX50 tem as mesmas características do IBrX100, mas apresenta a vantagem operacional de ser mais facilmente reproduzido pelo mercado. Ele é composto pelos 50 papéis mais líquidos da BOVESPA, escolhidos de acordo com os mesmos critérios do IBrX100 e devem ter presença mínima de $80 \%$ dos pregões. ${ }^{8}$

O índice FGV100 foi criado em 1986 pela Fundação Getulio Vargas, Rio de Janeiro. Sua carteira é formada por 100 papéis de 100 empresas privadas nãofinanceiras, tendo como critério de seleção a dimensão das empresas, o desempenho econômico-financeiro e a liquidez das ações negociados na BOVESPA e na Sociedade Operadora de Mercado de Acesso - SOMA. ${ }^{9}$

\section{Metodologia}

Este trabalho estuda o efeito no preço e no volume de transações das ações que entraram ou saíram do IBOVESPA, do IBrX50, do IBrX100 e do índice FGV100. Optou-se por utilizar a metodologia de estudo de evento, pois se trata de um método apropriado para a avaliação das hipóteses testadas neste artigo. Tal metodologia permite verificar a existência de retornos e volumes inesperados associados a um evento, centrando-se na data do mesmo.

Brown e Warner $(1980,1985)$ sugerem três modelos que podem ser utilizados para calcular os retornos anormais em estudos de eventos. Esses modelos são: o modelo de retornos ajustados à média, o modelo de retornos ajustados ao mercado e o modelo de retornos ajustados ao risco e ao mercado. Kloeckner (1995) verificou que os três modelos anteriores estimam os retornos anormais de forma consistente e similar em exame de situações no Brasil. Dessa forma, optou-se por calcular os retornos anormais segundo ambos o modelo de retornos ajustados ao mercado e o modelo de retornos ajustados ao risco e ao mercado. O modelo de retornos ajustados ao mercado é equivalente ao modelo de retornos ajustado ao risco

\footnotetext{
${ }^{7}$ Para maiores detalhes consultar www.bovespa.com.br/Pdf/Indices/IBrX.pdf

${ }^{8}$ Para maiores detalhes consultar www.bovespa.com.br/Pdf/Indices/IBrX50.pdf.

${ }^{9}$ Para maiores detalhes consultar www2.fgv.br/dgd/asp/dsp_FGV100.asp.
} 
e ao mercado, na hipótese de que os parâmetros calculados durante o período de estimação seja de intercepto igual a zero e beta igual a um. Avaliou-se a existência de retornos anormais das ações estudadas em uma janela de evento de 11 dias com o ponto médio (data "0") na data da efetiva alteração dos índices. Além disso, para o caso do IBOVESPA, avaliou-se também os retornos anormais em torno da data da prévia da BOVESPA que ocorre 30 dias antes da data efetiva da alteração do índice.

Para o cálculo dos retornos diários utilizou-se a fórmula abaixo:

$$
R_{i t}=\log \left(P_{i t}\right)-\log \left(P_{i t-1}\right)
$$

sendo $R_{i t}$ o retorno da ação $i$ na data $t$ e $P_{i t}$ o preço da ação $i$ na data $t$.

Para o cálculo dos retornos anormais utilizando o modelo de mercado utilizouse a fórmula abaixo:

$$
R A 1_{i t}=R_{i t}-R_{m t}
$$

$R A 1_{i t}$ é o retorno anormal da ação $i$ na data $t$ calculado através do modelo de mercado;

$R_{i t}$ é o retorno da ação na data $t$; e

$R_{m t}$ é o retorno do portafólio de mercado na data $t$.

Para o cálculo dos retornos anormais utilizando o modelo de retornos ajustado ao risco e ao mercado utilizou-se a fórmula abaixo:

$$
R A 2_{i t}=R_{i t}-\alpha_{i}-\beta_{i}^{*} R_{m t}
$$

$R A 2_{i t}$ é o retorno anormal da ação $i$ na data $t$ calculado através do modelo de retornos ajustado ao risco e ao mercado;

$R_{i t}$ é o retorno da ação na data $t$; e

$R_{m t}$ é o retorno do portafólio de mercado na data $t$. Os parâmetros $\alpha$ e $\beta$ foram estimados durante o período composto dos dias -120 até -6 em relação à data do evento utilizando o modelo de mercado.

Nesse artigo utiliza-se o retorno do índice FGV100 como carteira de mercado para retornos anormais quando as ações são adicionadas ou excluídas ao IBOVESPA, ao IBrX50 e ao IBrX100 e o IBOVESPA como carteira de mercado para as ações adicionadas ou excluídas ao índice FGV100. No caso do estudo de evento em torno da prévia da alteração do IBOVESPA também se utilizou o índice FGV100 como carteira de mercado. ${ }^{10}$

\footnotetext{
${ }^{10}$ Os nossos resultados apresentam as mesmas inferências se utilizarmos o próprio índice como carteira de mercado (i.e., se utilizarmos o índice IBOVESPA como carteira de mercado pra testes das alterações do índice IBOVESPA).
} 
Os retornos anormais médios foram agregados em uma seqüência cronológica de modo que quantifiquem a variação anormal ao longo do tempo, definindo, então, um retorno anormal cumulativo no período em estudo (Mackinlay, 1997).

$$
R A C_{t}=\sum R A_{t}
$$

$R A C_{t}$ é o retorno anormal cumulativo da ação entre o início da janela do evento e a data $t$ e $R A_{t}$ é o retorno anormal médio no instante $t$.

Além disso, realizou-se uma análise do volume de ações negociado em torno das datas de alteração nas composições das carteiras. O volume anormal foi computado segundo a equação abaixo:

$$
V A_{i t}=\left(V_{i t} / V_{i m}\right)-1
$$

$V A_{i t}$ é o volume anormal da ação $i$ na data $t$;

$V_{i t}$ é o volume de títulos negociados da ação na data $t$ e

$V_{i m}$ é o volume médio de negociação calculado nos 30 dias de negociação anteriores ao início da janela do evento (data de -35 a -6).

\section{Descrição da Amostra}

Para a definição da amostra foram selecionadas empresas com cotações na versão de 2002 do banco de dados Economática e suplementados com cotações fornecidas pela BOVESPA. Para as cotações e cálculos dos retornos utilizaramse as cotações de fechamento diárias de cada ação ajustada para o pagamento de dividendos. Foram excluídos eventos em que a ação não foi negociada por mais de cinco dias durante a janela do evento. ${ }^{11}$ A Tabela 1 apresenta o número de alterações em cada índice durante o período e a amostra utilizada neste artigo.

Durante o período estudado, foram adicionadas 64 ações à composição do IBOVESPA e 62 ações foram excluídas deste índice. Dessa amostra, utilizaram-se uma amostra de 47 eventos com adição e 37 com exclusão ao índice. Da mesma forma, o IBrX50 sofreu oito adições e oito remoções na composição da carteira ao longo do período estudado sendo que destas utilizamos oito adições e cinco remoções como amostra no presente estudo. O IBrX100 foi o índice que sofreu o maior número de alterações, o que era esperado pela maior quantidade de títulos incluídos na carteira. No total existiram 212 adições e remoções na composição da carteira sendo que destas utilizamos 168 adições e 113 remoções na nossa amostra. Finalmente, o índice FGV100 sofreu 96 adições e remoções durante os anos de 2000 a 2002 sendo que destas utilizamos 60 adições e 22 remoções na nossa amostra. Vale notar, que o nosso critério de no máximo cinco dias sem negociação durante a janela do evento tem maior impacto nas remoções do que adições aos índices devido à baixa liquidez desses títulos motivo este que é a própria causa das exclusões dos índices.

\footnotetext{
${ }^{11}$ A utilização do critério de três dias não altera a inferência dos resultados apresentados.
} 
Tabela 1

Descrição da Amostra

\begin{tabular}{|c|c|c|c|c|}
\hline \multicolumn{5}{|c|}{$\begin{array}{l}\text { A tabela apresenta o número de alterações nas } \\
\text { composições das carteiras do IBOVESPA, do IBrX50, } \\
\text { do IBrX100, e do índice FGV100 ao longo dos anos } \\
1994 \text { e } 2002 \text {. A tabela também apresenta o respectivo } \\
\text { número de eventos utilizados na nossa amostra para cada } \\
\text { índice }\end{array}$} \\
\hline & \multicolumn{2}{|c|}{ Eventos Totais } & \multicolumn{2}{|c|}{ Amostra Final } \\
\hline Índice & Entrada & Saída & Entrada & Saída \\
\hline IBOVESPA & 64 & 62 & 47 & 37 \\
\hline IBrX50 & 8 & 8 & 8 & 5 \\
\hline $\mathrm{IBrX} 100$ & 212 & 212 & 168 & 113 \\
\hline FGV100 & 96 & 96 & 60 & 22 \\
\hline
\end{tabular}

A Tabela 2 apresenta a lista de todas as empresas adicionadas e excluídas ao IBOVESPA e a marcação daquelas utilizadas na nossa amostra. ${ }^{12} \mathrm{~A}$ tabela também apresenta a data de alteração nas carteiras para cada um dos casos. Pode-se constatar que os eventos estão proporcionalmente distribuídos ao longo do tempo diminuindo à preocupação de sobreposição da janela de evento. Ainda assim, notase que existem mais de um evento em algumas datas de alteração da carteira (por exemplo, na data de 5/1/2000, o IBOVESPA sofreu a adição das ações EMBRAER PN e EMBRATEL PAR ON), o que pode causar dependência entre os eventos ocorridos na mesma data.

Tabela 2

Lista Das Empresas Adicionadas e Excluídas no IBOVESPA

\begin{tabular}{lccccccc}
\hline Ação & Data & Alteração & Amostra & Ação & Data & Alteração & Amostra \\
\hline ACESITA PN & $1 / 1 / 1995$ & Entrada & $\mathrm{S}$ & EMBRAER ON & $1 / 1 / 2000$ & Entrada & $\mathrm{S}$ \\
ACESITA PN & $5 / 1 / 1999$ & Saída & $\mathrm{S}$ & EMBRAER PN & $5 / 1 / 2000$ & Entrada & $\mathrm{S}$ \\
ACESITA PN & $5 / 1 / 2000$ & Entrada & $\mathrm{S}$ & EMBRATEL PAR ON & $5 / 1 / 2000$ & Entrada & $\mathrm{S}$ \\
AÇOS VILLRES PN & $9 / 1 / 1995$ & Saída & $\mathrm{N}$ & EMBRATEL PAR PN & $5 / 1 / 2000$ & Entrada & $\mathrm{S}$ \\
ALPARGATAS PN & $5 / 1 / 1997$ & Saída & $\mathrm{S}$ & EPTE PN & $1 / 1 / 1998$ & Entrada & $\mathrm{S}$ \\
AMBEV PN & $1 / 1 / 2001$ & Entrada & $\mathrm{S}$ & EPTE PN & $9 / 1 / 1999$ & Saída & $\mathrm{S}$ \\
AQUATEC PN & $9 / 1 / 1994$ & Saída & $\mathrm{S}$ & ERICSSON PN & $5 / 1 / 1999$ & Saída & $\mathrm{S}$ \\
BANESPA PN & $5 / 1 / 2001$ & Saída & $\mathrm{S}$ & ESTRELA PN & $5 / 1 / 1996$ & Saída & $\mathrm{S}$ \\
BELG MINEIR ON & $5 / 1 / 1998$ & Saída & $\mathrm{N}$ & GER PARANAP PN & $5 / 1 / 2000$ & Saída & $\mathrm{S}$ \\
BELGO MIN PN & $5 / 1 / 1999$ & Saída & $\mathrm{S}$ & GER PARANAP PN & $9 / 1 / 1999$ & Entrada & $\mathrm{S}$ \\
BOMBRIL PN & $1 / 1 / 1996$ & Saída & $\mathrm{S}$ & GER TIETE PN & $9 / 1 / 1999$ & Entrada & $\mathrm{N}$ \\
BRADESPAR PN & $9 / 1 / 2000$ & Entrada & $\mathrm{S}$ & GER TIETE PN & $9 / 1 / 2000$ & Saída & $\mathrm{N}$ \\
BRAHMA PN & $1 / 1 / 2001$ & Saída & $\mathrm{N}$ & GERASUL ON & $5 / 1 / 2002$ & Saída & $\mathrm{N}$ \\
BRASIL T PAR ON & $9 / 1 / 2000$ & Entrada & $\mathrm{S}$ & GERASUL ON & $5 / 1 / 1998$ & Entrada & $\mathrm{N}$ \\
BRASIL T PAR PN & $9 / 1 / 2000$ & Entrada & $\mathrm{S}$ & GERASUL PNB & $5 / 1 / 1998$ & Entrada & $\mathrm{N}$ \\
BRASIL TELEC PN & $9 / 1 / 2000$ & Entrada & $\mathrm{S}$ & GERASUL PNB & $9 / 1 / 1999$ & Saída & $\mathrm{N}$ \\
BRASKEM PNA & $9 / 1 / 2002$ & Entrada & $\mathrm{S}$ & GERDAU PN & $9 / 1 / 2000$ & Entrada & $\mathrm{S}$ \\
BRASMOTOR PN & $5 / 1 / 2000$ & Saída & $\mathrm{N}$ & GLOBO CABO PN & $5 / 1 / 2000$ & Entrada & $\mathrm{N}$ \\
CAEMI METAL PN & $9 / 1 / 1996$ & Saída & $\mathrm{S}$ & GLOBO CABO PN & $9 / 1 / 2002$ & Saída & $\mathrm{N}$
\end{tabular}

\footnotetext{
${ }^{12} \mathrm{~A}$ lista de empresas adicionadas e excluídas aos demais índices está disponível com os autores, caso necessário. Optamos por incluir apenas no IBOVESPA, pois consideramos este o de maior importância entre os índices utilizados.
} 


\begin{tabular}{|c|c|c|c|c|c|c|c|}
\hline Ação & Data & Alteração & Amostra & Ação & Data & Alteração & Amostra \\
\hline CELESC PNB & $1 / 1 / 1998$ & Entrada & $\mathrm{S}$ & INEPAR PN & 9/1/1997 & Entrada & $\mathrm{S}$ \\
\hline CEMIG ON & $5 / 1 / 1997$ & Entrada & $\mathrm{S}$ & LIGHTPAR ON & 9/1/1997 & Entrada & $\mathrm{S}$ \\
\hline CESP PN & $5 / 1 / 1994$ & Entrada & $\mathrm{S}$ & LIGHTPAR ON & $5 / 1 / 1999$ & Saída & $\mathrm{S}$ \\
\hline CEVAL PN & $5 / 1 / 1999$ & Saída & $\mathrm{N}$ & MANNESMANN ON & $9 / 1 / 1994$ & Saída & S \\
\hline CIM ITAU PN & $5 / 1 / 1997$ & Saída & $\mathrm{S}$ & METAL BARBAR PN & $5 / 1 / 1996$ & Saída & $\mathrm{N}$ \\
\hline COFAP PN & $1 / 1 / 1998$ & Saída & S & METAL LEVE PN & $5 / 1 / 1995$ & Saída & S \\
\hline COMGAS PNA & $9 / 1 / 2001$ & Entrada & S & NACIONAL PN & $1 / 1 / 1996$ & Saída & $\mathrm{N}$ \\
\hline COPEL PNB & 9/1/1999 & Entrada & $\mathrm{S}$ & NET PN & $9 / 1 / 2002$ & Entrada & $\mathrm{S}$ \\
\hline COPENE PN & $9 / 1 / 2002$ & Saída & $\mathrm{N}$ & PAPEL SIMAO PN & $5 / 1 / 1995$ & Saída & $\mathrm{N}$ \\
\hline COPESUL ON & $9 / 1 / 2000$ & Saída & S & PARANAPAN PN & $1 / 1 / 1999$ & Saída & $\mathrm{N}$ \\
\hline COPESUL ON & $9 / 1 / 1995$ & Entrada & S & PAUL F LUZ ON & 9/1/1999 & Saída & S \\
\hline COSIPA PNB & $5 / 1 / 1995$ & Entrada & $\mathrm{N}$ & PETROBRAS ON & $1 / 1 / 2000$ & Entrada & $\mathrm{S}$ \\
\hline COSIPA PNB & $5 / 1 / 1999$ & Saída & $\mathrm{N}$ & REFRIPAR PN & $5 / 1 / 1997$ & Saída & S \\
\hline CRT CEL PNA & $9 / 1 / 2000$ & Entrada & S & SABESP ON & $5 / 1 / 2000$ & Entrada & S \\
\hline CRT PNA & $1 / 1 / 2001$ & Saída & $\mathrm{S}$ & SADIA CON PN & $9 / 1 / 1998$ & Saída & $\mathrm{N}$ \\
\hline CRT PNA & $9 / 1 / 2000$ & Entrada & $\mathrm{S}$ & SHARP PN & $5 / 1 / 1999$ & Saída & $\mathrm{S}$ \\
\hline DURATEX PN & $9 / 1 / 2000$ & Saída & $\mathrm{S}$ & SID RIOGRANDE PN & 9/1/1997 & Saída & $\mathrm{N}$ \\
\hline EBEN PN & $1 / 1 / 1998$ & Entrada & $\mathrm{N}$ & SID TUBARAO PNB & $9 / 1 / 1994$ & Entrada & $\mathrm{N}$ \\
\hline EBEN PN & $9 / 1 / 1999$ & Saída & S & SIDERURG NAC ON & $9 / 1 / 1994$ & Entrada & S \\
\hline ELETROBRAS ON & $5 / 1 / 1994$ & Entrada & S & SUZANO PN & $5 / 1 / 1995$ & Saída & S \\
\hline ELETROLUX PN & $5 / 1 / 1997$ & Entrada & $S$ & TEF DATA BRA PN & $9 / 1 / 2001$ & Entrada & $S$ \\
\hline ELETROLUX PN & $5 / 1 / 1998$ & Saída & $\mathrm{N}$ & TEF DATA BRA PN & $9 / 1 / 2002$ & Saída & $\mathrm{S}$ \\
\hline ELETROPAULO PNB & 9/1/1997 & Entrada & $\mathrm{S}$ & TEL SUDESTE PN & $9 / 1 / 2000$ & Saída & $\mathrm{S}$ \\
\hline EMAE PN & $1 / 1 / 1998$ & Entrada & S & TELE CL SUL ON & $9 / 1 / 2000$ & Entrada & S \\
\hline EMAE PN & $5 / 1 / 1999$ & Saída & S & TELE CL SUL PN & $5 / 1 / 2000$ & Entrada & S \\
\hline TELE CTR OES PN & $5 / 1 / 2000$ & Entrada & S & TELERJ PN & $1 / 1 / 2002$ & Saída & $\mathrm{N}$ \\
\hline TELE CTR SUL ON & $5 / 1 / 2000$ & Entrada & $\mathrm{N}$ & TELERJ PN & 9/1/1997 & Entrada & $\mathrm{N}$ \\
\hline TELE CTR SUL ON & $9 / 1 / 2000$ & Saída & $\mathrm{N}$ & TELES RCT ON & $5 / 1 / 2000$ & Saída & S \\
\hline TELE CTR SUL PN & $5 / 1 / 2000$ & Entrada & $\mathrm{N}$ & TELES RCT PN & $5 / 1 / 2000$ & Saída & S \\
\hline TELE CTR SUL PN & $9 / 1 / 2000$ & Saída & $\mathrm{N}$ & TELES RCTB ON & 1/1/1999 & Entrada & $\mathrm{S}$ \\
\hline TELE LESTE CL PN & $9 / 1 / 2000$ & Entrada & $\mathrm{S}$ & TELES RCTB PN & 1/1/1999 & Entrada & S \\
\hline TELE NORD CL PN & $5 / 1 / 2000$ & Entrada & S & TELESP CEL ON & $5 / 1 / 1998$ & Entrada & S \\
\hline TELE SUDESTE PN & $5 / 1 / 2000$ & Entrada & $S$ & TELESP CEL PNB & $5 / 1 / 1998$ & Entrada & S \\
\hline TELEBRAS ON & $1 / 1 / 1999$ & Saída & $\mathrm{N}$ & TELESP CL ON & 9/1/1999 & Saída & $\mathrm{N}$ \\
\hline TELEBRAS PN & $1 / 1 / 1999$ & Saída & $\mathrm{N}$ & TELESP CL ON & $5 / 1 / 2000$ & Entrada & S \\
\hline TELEMAR N L PNA & $1 / 1 / 2002$ & Entrada & S & TELESP CLPA ON & $9 / 1 / 2000$ & Saída & S \\
\hline TELEMAR ON & $5 / 1 / 2000$ & Entrada & $\mathrm{S}$ & TELESP ON & $9 / 1 / 2000$ & Saída & $\mathrm{S}$ \\
\hline TELEMAR PN & $5 / 1 / 2000$ & Entrada & $\mathrm{S}$ & TRACTEBEL ON & $5 / 1 / 2002$ & Entrada & $\mathrm{S}$ \\
\hline TELEMIG PART PN & $9 / 1 / 2000$ & Entrada & S & TRANS PAULIST PN & $9 / 1 / 1999$ & Entrada & S \\
\hline TELEPAR CEL PNB & $5 / 1 / 1998$ & Entrada & $\mathrm{S}$ & UNIPAR PNB & $5 / 1 / 1999$ & Saída & S \\
\hline TELEPAR CL PNB & $9 / 1 / 1999$ & Saída & S & VARIG PN & $9 / 1 / 1994$ & Saída & S \\
\hline TELEPAR PN & $9 / 1 / 2000$ & Saída & $\mathrm{N}$ & VCP PN & $5 / 1 / 1995$ & Entrada & S \\
\hline TELERJ CEL PNB & $5 / 1 / 1998$ & Entrada & S & VIDR S MARINA ON & $1 / 1 / 1995$ & Saída & $\mathrm{N}$ \\
\hline TELERJ CL PNB & 9/1/1999 & Saída & $\mathrm{S}$ & WHIT MART ON & $9 / 1 / 2000$ & Saída & $\mathrm{N}$ \\
\hline
\end{tabular}




\section{Análise dos Resultados}

\subsection{Estudo de evento - retornos anormais}

Nesta seção apresentam-se os resultados da análise de estudo de evento. Conforme descrito na seção 2, calcularam-se os retornos anormais para cada dia da janela do evento com base no modelo de retorno ajustado ao mercado, o modelo de retorno ajustado ao risco e ao mercado e os respectivos retornos anormais cumulativos durante a janela do evento. Para o caso do IBOVESPA, o estudo de evento foi feito em torno da data da prévia da BOVESPA e da data efetiva da alteração da carteira. Neste caso é possível avaliar o efeito do anúncio separadamente do efeito da alteração na carteira. Para os demais índices a análise foi feita somente na data da efetivação devido à falta de uma data específica do anúncio ou coincidência com as datas das alterações.

A Tabela 3 - Painel A apresenta os resultados para as ações adicionadas ao índice IBOVESPA em torno da data da prévia fornecida pela BOVESPA anunciada 30 dias antes da alteração da carteira do IBOVESPA. Neste caso, não existe evidência de retornos anormais positivos na data do evento. Utilizando-se o modelo de mercado, encontraram-se retornos anormais negativos e significativos nas datas "- 3 " e "-2" e um retorno anormal positivo e significativo na data "+4". A tabela também apresenta o percentual de empresas com retornos anormais positivos em cada dia da janela do evento. Esse resultado completa os retornos anormais, pois não é afetado pela não normalidade dos retornos. Neste caso, o dia de maior freqüência de retornos positivos foi na data “ +1 ”. Em relação aos retornos anormais cumulativos, encontraram-se retornos anormais cumulativos em torno da data da prévia da BOVESPA para as alterações no IBOVESPA.

A Tabela 3 - Painel B apresenta uma análise similar para as ações excluídas do IBOVESPA. Neste caso praticamente não existe evidência de comportamento anormal em torno da data da prévia fornecida pela BOVESPA (a única exceção foi um retorno anormal negativo na data “-3"). O Painel C apresenta o teste de diferenças de médias para o retorno anormal cumulativo durante as datas de "-2" até " 0 ". Não foram encontradas diferenças entre os retornos anormais cumulativos em torno da data da prévia entre ações adicionadas e excluídas ao IBOVESPA.

Em geral, a ausência de retornos anormais em torno do anúncio das alterações do IBOVESPA contrasta com resultados obtidos nos Estados Unidos. Uma possível explicação para o fato é que a BOVESPA adota critérios definidos para a inclusão e a exclusão de uma companhia na carteira. Neste caso, é possível que os investidores antecipem a alteração da composição do IBOVESPA o que torna a data da prévia fornecida pela BOVESPA não informativa. 
Tabela 3

Retornos Anormais Percentuais para as Alterações no IBOVESPA - Data da Prévia da BOVESPA

A tabela apresenta os retornos anormais diários e retornos anormais cumulativos para cada dia da janela do evento para a amostra de alterações no IBOVESPA. A tabela também apresenta estatísticas descritivas e testes de significâncias para os retornos anormais diários. O Painel C apresenta o teste de diferença de médias para os retorno anormal cumulativo durante as data -2 a 0. ***, **, *: Níveis de significância de 1\%,5\% e 10\% respectivamente.

Painel A - Adições no IBOVESPA

\begin{tabular}{|c|c|c|c|c|c|c|c|c|c|c|c|}
\hline Data & -5 & -4 & -3 & -2 & -1 & 0 & 1 & 2 & 3 & 4 & 5 \\
\hline Retorno Anormal 1 & $-0,51$ & 0,25 & $-0,96^{* * *}$ & $-1,03 * *$ & $-0,51$ & $-0,8$ & $-0,01$ & $-0,51$ & 0,05 & $0,78^{*}$ & $-0,68$ \\
\hline Teste T & $-1,61$ & 0,64 & $-2,06$ & $-2,47$ & $-0,91$ & $-1,12$ & $-0,01$ & $-0,99$ & 0,09 & 1,93 & $-1,61$ \\
\hline$\%$ RA $1 \geq 0$ & 0,4 & 0,49 & 0,36 & 0,4 & 0,38 & 0,49 & 0,58 & 0,49 & 0,51 & 0,53 & 0,4 \\
\hline CAR 1 & $-0,51$ & $-0,26$ & $-1,22$ & $-2,26 * *$ & $-2,77 * *$ & $-3,56^{* *}$ & $-3,57^{* *}$ & $-4,08^{* * *}$ & $-4,03 *$ & $-3,25$ & $-3,93$ \\
\hline Teste T & $-1,61$ & $-0,43$ & $-1,36$ & $-2,1$ & $-2,06$ & $-2,36$ & $-2,02$ & $-2,17$ & -2 & $-1,57$ & $-1,72$ \\
\hline Retorno Anormal 2 & $-0,83^{*}$ & $-0,29$ & $-0,94 * *$ & $-0,95 * *$ & 0,05 & $-0,68$ & 0,06 & $-0,78$ & $-0,45$ & 0,26 & $-0,3$ \\
\hline Teste T & $-1,8$ & $-0,52$ & $-2,27$ & $-2,1$ & 0,11 & $-0,86$ & 0,1 & $-1,12$ & $-0,96$ & 0,6 & $-0,85$ \\
\hline$\%$ RA $2 \geq 0$ & 0,44 & 0,53 & 0,31 & 0,38 & 0,42 & 0,53 & 0,6 & 0,47 & 0,42 & 0,49 & 0,47 \\
\hline CAR 2 & $-0,83^{*}$ & $-1,12$ & $-2,06^{*}$ & $-3,01 * *$ & $-2,96^{*}$ & $-3,64 *$ & $-3,58$ & $-4,36^{*}$ & $-4,81^{*}$ & $-4,55 *$ & $-4,85 *$ \\
\hline Teste T & $-1,8$ & $-1,2$ & $-1,73$ & $-2,28$ & $-1,94$ & $-1,95$ & $-1,66$ & $-1,77$ & $-1,9$ & $-1,74$ & $-1,77$ \\
\hline \multicolumn{12}{|c|}{ Painel B - Exclusões no IBOVESPA } \\
\hline Data & -5 & -4 & -3 & -2 & -1 & 0 & 1 & 2 & 3 & 4 & 5 \\
\hline Retorno Anormal 1 & $-0,19$ & 0,34 & 0,06 & $-0,35$ & 0,92 & $-0,15$ & 0,19 & 0,01 & $-1,43^{* * *}$ & $-0,09$ & $-0,07$ \\
\hline Teste T & $-0,31$ & 0,67 & 0,11 & $-0,62$ & 1,15 & $-0,19$ & 0,27 & 0,01 & $-2,22$ & $-0,14$ & $-0,13$ \\
\hline$\%$ RA $1 \geq 0$ & 0,53 & 0,58 & 0,47 & 0,53 & 0,53 & 0,42 & 0,39 & 0,39 & 0,29 & 0,47 & 0,5 \\
\hline CAR 1 & $-0,19$ & 0,15 & 0,2 & $-0,15$ & 0,77 & 0,63 & 0,82 & 0,82 & $-0,61$ & $-0,7$ & $-0,77$ \\
\hline Teste T & $-0,31$ & 0,19 & 0,25 & $-0,17$ & 0,73 & 0,48 & 0,57 & 0,58 & $-0,5$ & $-0,58$ & $-0,62$ \\
\hline Retorno Anormal 2 & $-0,44$ & 0,31 & $-0,07$ & $-0,74$ & 0,57 & $-0,69$ & 0,08 & 0,18 & $-1,22^{*}$ & $-0,04$ & $-0,35$ \\
\hline Teste T & $-0,66$ & 0,63 & $-0,14$ & $-1,28$ & 0,7 & $-0,81$ & 0,11 & 0,31 & $-1,87$ & $-0,06$ & $-0,62$ \\
\hline$\%$ RA $2 \geq 0$ & 0,47 & 0,53 & 0,45 & 0,42 & 0,5 & 0,37 & 0,39 & 0,45 & 0,39 & 0,53 & 0,53 \\
\hline CAR 2 & $-0,44$ & $-0,12$ & $-0,2$ & $-0,94$ & $-0,37$ & $-1,06$ & $-0,98$ & $-0,8$ & $-2,02$ & $-2,06$ & $-2,4$ \\
\hline Teste T & $-0,66$ & $-0,16$ & $-0,24$ & $-1,05$ & $-0,33$ & $-0,68$ & $-0,57$ & $-0,43$ & $-1,17$ & $-1,25$ & $-1,35$ \\
\hline \multicolumn{12}{|c|}{ Painel C - Diferenças de médias - Retorno anormal cumulativo durante os dias $-2 \mathrm{e} 0$} \\
\hline Data & Entrada & Saída & T-Teste & & & & & & & & \\
\hline CAR1 & $-2,34$ & 0,42 & $-1,52$ & & & & & & & & \\
\hline CAR2 & $-1,58$ & $-0,86$ & $-0,34$ & & & & & & & & \\
\hline
\end{tabular}


A Tabela 4 - Painel A apresenta os resultados para as ações adicionadas ao IBOVESPA em torno da data efetiva da alteração da carteira. Da amostra total de 47 eventos adicionados ao índice, constatou-se utilizando o modelo de mercado um retorno anormal médio positivo de $2,26 \%$ e de $2,38 \%$ segundo o modelo ajustado ao risco e ao mercado ambos para a data "-1" (com significância de 1\%). Em torno da data " -1 ", $64 \%$ das empresas apresentaram retornos anormais positivos no modelo de mercado e $72 \%$ no modelo ajustado ao risco e ao mercado. No entanto, observaram-se retornos anormais negativos nas datas “ 0 ", “+1", "+2" e "+3" sugerindo que a evolução inicial nos preços foi seguida por uma queda nos preços destas ações. Essa conclusão pode ser comprovada pelo retorno anormal cumulativo no final da janela do evento.

A Tabela 4 - Painel B apresenta uma análise similar para as ações excluídas do IBOVESPA. Vale notar que, devido à falta de negociação destas ações, removeram-se 25 eventos que continham mais de cinco dias sem negociação durante a janela do evento. Da amostra total de 37 eventos, constatou-se um retorno anormal médio negativo iniciando-se em torno da data "-3" até a data da efetiva alteração na carteira (data do evento). O Painel $\mathrm{C}$ apresenta o teste de diferenças de médias para o retorno anormal cumulativo durante as datas de "-2" a "0". Utilizando-se o modelo de mercado (modelo ajustado ao risco e ao mercado) contatou-se um retorno anormal cumulativo médio igual a $1,94 \%(0,39 \%)$ para as ações adicionadas e $-3,70 \%(-3,50 \%)$ para as ações excluídas ao IBOVESPA com diferença significativa ao nível de $1 \%$.

A Figura 1 apresenta o comportamento dos retornos anormais acumulados para a amostra. Uma constatação importante é que, para as ações adicionadas ao IBOVESPA, os retornos anormais acumulados retornaram ao valor inicial dois dias após a data do evento. Estes resultados sugerem uma elevação temporária no preço das ações adicionadas ao índice e que retornaram ao valor inicial. Para as ações excluídas do índice, observam-se retornos anormais negativos e permanentes ao final da janela do evento. Em geral, os resultados encontrados são consistentes com um aumento de demanda temporária pelos títulos adicionados e uma redução na demanda por papéis excluídos ao IBOVESPA. Uma explicação para este resultado deve-se ao ajustamento das carteiras de fundos de investimento replicadores de índices. 
Alterações ao IBOVESPA

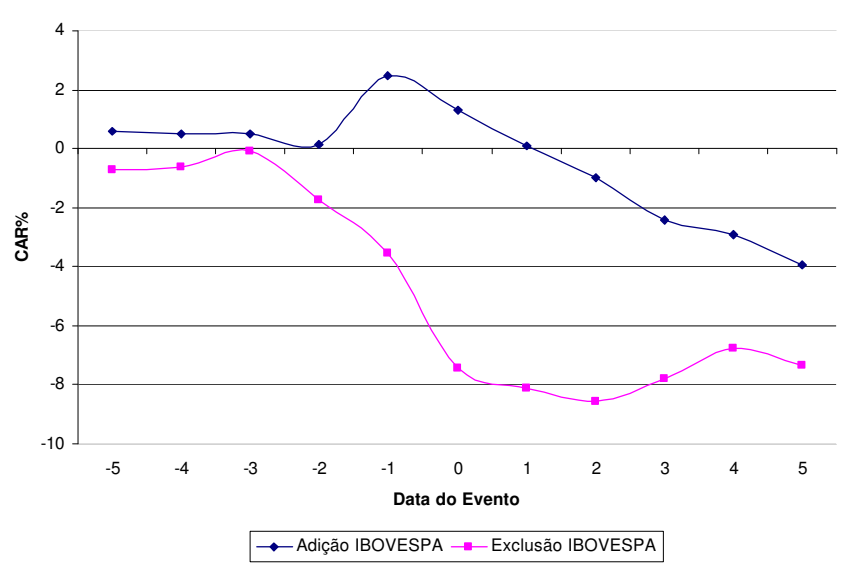

Figura 1

Retorno Anormal Cumulativo - Alterações no IBOVESPA

A figura apresenta uma evolução dos retornos anormais cumulativos durante a janela do evento para a amostra de alterações no IBOVESPA.

A Tabela 5 - Painel A apresenta os resultados para as ações adicionadas ao IBrX50. Vale notar que devido ao pequeno número de alterações neste índice, a significância estatística dos resultados é pequena. Da amostra total de oito eventos adicionados ao índice, constatou-se retornos anormais médios positivos de $2,56 \%$ e $1,60 \%$ na data do evento dependendo do modelo para o cálculo dos retornos anormais. Os resultados para as ações excluídas ao índice (Tabela 5 - Painel B) são menos conclusivos, observando-se uma instabilidade nos preços das ações a partir da data do evento. O Painel $\mathrm{C}$ apresenta o teste de diferenças de médias para o retorno anormal cumulativo da data "-2" até " 0 ". Neste caso, não se encontrou diferenças significativa entre os retornos anormais cumulativos das ações adicionadas e excluídas ao IBrX50.

A Figura 2 apresenta o comportamento dos retornos anormais acumulados para a amostra. Consistente com os resultados da amostra de alterações ao IBOVESPA (Figura 1), observa-se um aumento de preço nas ações adicionadas ao índice que retorna ao valor inicial ao final da janela do evento. No entanto, para os eventos de exclusão do IBr50, documenta-se um retorno anormal cumulativo negativo e estável antes da data do evento com a presença de retornos anormais instáveis após a data do evento. Vale lembrar que estes resultados devem ser tomados com cautela dado ao pequeno número de eventos e a baixa significância estatística dos testes. 
A tabela apresenta os retornos anormais diários e retornos anormais cumulativos para cada dia da janela do evento para a amostra de alterações no IBOVESPA. A tabela também apresenta estatísticas descritivas e testes de significâncias para os retornos anormais diários. O Painel C apresenta o teste de diferença de médias para os retorno anormal cumulativo durante as data -2 a $0 . * * *, * *, *$ : Níveis de significância de $1 \%, 5 \%$ e $10 \%$ respectivamente.

\begin{tabular}{|c|c|c|c|c|c|c|c|c|c|c|c|}
\hline Data & -5 & -4 & -3 & -2 & -1 & 0 & 1 & 2 & 3 & 4 & 5 \\
\hline Retorno Anormal 1 & 0,64 & 0,62 & 0,25 & 0,41 & $2,26 * * *$ & $-1,53^{*}$ & $-1,83^{* * * *}$ & $-1,48^{* * * *}$ & $-1,22^{* * * *}$ & 0,41 & $-1,25 * * *$ \\
\hline Teste T & 1,39 & 1,58 & 0,74 & 0,79 & 3,68 & $-1,99$ & $-3,22$ & $-3,47$ & $-2,98$ & 0,92 & $-3,24$ \\
\hline$\%$ RA $1 \geq 0$ & 0,55 & 0,6 & 0,6 & 0,53 & 0,64 & 0,38 & 0,3 & 0,28 & 0,38 & 0,49 & 0,28 \\
\hline CAR 1 & 0,64 & $1,26^{*}$ & $1,51^{* *}$ & $1,92 *$ & $4,18 * * *$ & $2,66^{*}$ & 0,83 & $-0,66$ & $-1,88$ & $-1,48$ & $-2,73^{*}$ \\
\hline Teste T & 1,39 & 2 & 2,03 & 1,86 & 3,26 & 1,94 & 0,62 & $-0,46$ & $-1,33$ & $-1,11$ & $-1,87$ \\
\hline Retorno Anormal 2 & $-0,27$ & $0,87 * *$ & $-0,27$ & 0,41 & $2,38 * * *$ & $-2,40 * * *$ & $-2,33 * * *$ & $-1,63 * * *$ & $-1,42^{* * * *}$ & $0,90^{*}$ & $-0,59$ \\
\hline Teste T & $-0,57$ & 2,14 & $-0,72$ & 0,74 & 3,77 & $-3,01$ & $-3,67$ & $-3,35$ & $-3,04$ & 1,93 & $-1,04$ \\
\hline$\%$ RA $2 \geq 0$ & 0,5 & 0,65 & 0,5 & 0,61 & 0,72 & 0,33 & 0,24 & 0,26 & 0,33 & 0,59 & 0,39 \\
\hline CAR $2-$ & $-0,27$ & 0,59 & 0,32 & 0,73 & $3,11 * *$ & 0,71 & $-1,61$ & $-3,24 *$ & $-4,65 * *$ & $-3,75 * *$ & $-4,34 * *$ \\
\hline Teste T & $-0,57$ & 0,93 & 0,39 & 0,6 & 2,06 & 0,43 & $-0,99$ & $-1,84$ & $-2,45$ & $-2,12$ & $-2,16$ \\
\hline \multicolumn{12}{|c|}{ Painel B - Exclusões no IBOVESPA } \\
\hline Data & -5 & -4 & -3 & -2 & -1 & 0 & 1 & 2 & 3 & 4 & 5 \\
\hline Retorno Anormal 1 & $-0,7$ & 0,58 & $-1,08^{*}$ & $-1,15^{*}$ & $-0,75$ & $-1,80^{* *}$ & 0,24 & $-0,54$ & 0,37 & 0,73 & $-0,15$ \\
\hline Teste $\mathrm{T}$ & $-1,26$ & 1,14 & $-1,97$ & $-1,99$ & $-0,98$ & $-2,31$ & 0,49 & $-1,1$ & 0,63 & 1,55 & $-0,34$ \\
\hline$\% \mathrm{RA} 1 \geq 0$ & 0,3 & 0,49 & 0,27 & 0,35 & 0,38 & 0,35 & 0,35 & 0,35 & 0,43 & 0,54 & 0,43 \\
\hline CAR 1 & $-0,7$ & $-0,13$ & $-1,2$ & $-2,35$ & $-3,11 *$ & $-4,90 * *$ & $-4,66^{* * *}$ & $-5,20 * * * *$ & $-4,83 * * *$ & $-4,10 * *$ & $-4,25^{* *}$ \\
\hline Teste T & $-1,26$ & $-0,16$ & $-1,09$ & $-1,59$ & $-1,87$ & $-2,51$ & $-2,46$ & $-2,85$ & $-2,93$ & $-2,56$ & $-2,37$ \\
\hline Retorno Anormal 2 & $-0,42$ & 0,67 & $-1,10^{* *}$ & $-1,10^{*}$ & $-0,75$ & $-1,66^{*}$ & 0,54 & $-0,7$ & 0,52 & 0,74 & $-0,03$ \\
\hline Teste T & $-0,67$ & 1,44 & $-2,08$ & $-1,95$ & $-1,01$ & $-2,02$ & 0,95 & $-1,14$ & 0,75 & 1,32 & $-0,04$ \\
\hline$\%$ RA $2 \geq 0$ & 0,38 & 0,51 & 0,38 & 0,38 & 0,38 & 0,43 & 0,49 & 0,35 & 0,46 & 0,57 & 0,59 \\
\hline CAR 2 & $-0,42$ & 0,25 & $-0,85$ & $-1,95$ & $-2,69$ & $-4,35 * *$ & $-3,81^{*}$ & $-4,51^{* *}$ & $-4,00^{*}$ & $-3,26$ & $-3,28$ \\
\hline Teste T & $-0,67$ & 0,3 & $-0,76$ & $-1,33$ & $-1,66$ & $-2,22$ & $-2,02$ & $-2,18$ & $-1,83$ & $-1,39$ & $-1,21$ \\
\hline \multicolumn{12}{|c|}{ Painel C - Diferenças de médias - Retorno anormal cumulativo durante os dias $-2 \mathrm{e} 0$} \\
\hline Data & Entrada & Saída & T-Teste & & & & & & & & \\
\hline CAR1 & 1,94 & $-3,7$ & $2,54^{* * *}$ & & & & & & & & \\
\hline CAR2 & 0,39 & $-3,5$ & $1,97 * *$ & & & & & & & & \\
\hline
\end{tabular}


Tabela 5

Retornos Anormais Percentuais para as Alterações no IBrX50

Esta tabela apresenta os retornos anormais diários e retornos anormais cumulativos para cada dia da janela do evento para a amostra de alterações no IBrX50. A tabela também apresenta estatísticas descritivas e testes de significâncias para os retornos anormais diários. O Painel C apresenta o teste de diferença de médias para os retorno anormal cumulativo durante as data -2 a 0 . ***, *** *: Níveis de significância de $1 \%, 5 \%$ e $10 \%$ respectivamente.

\begin{tabular}{|c|c|c|c|c|c|c|c|c|c|c|c|}
\hline 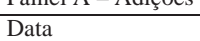 & $\frac{18}{-5}$ & -4 & -3 & -2 & -1 & 0 & 1 & 2 & 3 & 4 & 5 \\
\hline Retorno Anormal 1 & $-1,62$ & $-0,04$ & $-0,31$ & 1,11 & 0,28 & 2,56 & -1 & $-0,01$ & 0 & $-0,69$ & $-1,11$ \\
\hline Teste T & $-1,44$ & $-0,05$ & $-0,29$ & 0,79 & 0,14 & 1,24 & $-0,96$ & 0 & 0 & $-1,02$ & $-0,56$ \\
\hline$\%$ RA $1 \geq 0$ & 0,5 & 0,5 & 0,25 & 0,75 & 0,5 & 0,75 & 0,38 & 0,5 & 0,63 & 0,25 & 0,5 \\
\hline CAR 1 & $-1,62$ & $-1,65$ & $-1,96$ & $-0,85$ & $-0,56$ & 2 & 1 & 0,99 & 0,99 & 0,3 & $-0,81$ \\
\hline Teste T & $-1,44$ & $-1,02$ & $-1,25$ & $-0,85$ & $-0,33$ & 0,58 & 0,36 & 0,58 & 0,66 & 0,22 & $-0,26$ \\
\hline Retorno Anormal 2 & $-1,65$ & 2,17 & 1,38 & 0,95 & 0,45 & 1,6 & $-2,29$ & $-0,61$ & $-1,28$ & $-0,77$ & $-0,45$ \\
\hline Teste T & $-1,4$ & 1,04 & 1,16 & 0,69 & 0,2 & 1,06 & $-1,07$ & $-0,27$ & $-0,98$ & $-1,02$ & $-0,17$ \\
\hline$\%$ RA2 $\geq 0$ & 0,5 & 0,75 & 0,5 & 0,63 & 0,5 & 0,75 & 0,25 & 0,5 & 0,5 & 0,38 & 0,5 \\
\hline CAR $2-$ & $-1,65$ & 0,52 & 1,9 & 2,85 & 3,3 & 4,9 & 2,61 & 1,99 & 0,71 & $-0,06$ & $-0,51$ \\
\hline Teste T & $-1,4$ & 0,23 & 0,72 & 0,83 & 0,6 & 0,74 & 0,55 & 0,76 & 0,46 & $-0,04$ & $-0,13$ \\
\hline \multicolumn{12}{|c|}{ Painel B - Exclusões no IBrX50 } \\
\hline Data & -5 & -4 & -3 & -2 & -1 & $\overline{0}$ & 1 & 2 & 3 & 4 & 5 \\
\hline Retorno Anormal 1 & 0,08 & $-1,66^{* * *}$ & 0,1 & $-0,04$ & $-1,15^{*}$ & 0 & 0,74 & 0,81 & 1,57 & $-1,07$ & $-1,89$ \\
\hline Teste $\mathrm{T}$ & 0,07 & $-3,27$ & 0,3 & $-0,04$ & $-2,36$ & 0 & 0,94 & 1,52 & 1,09 & $-1,43$ & $-0,66$ \\
\hline$\% \mathrm{RA} 1 \geq 0$ & 0,4 & 0 & 0,2 & 0,6 & 0 & 0,6 & 0,6 & 0,6 & 0,8 & 0,4 & 0,4 \\
\hline CAR 1 & 0,08 & $-1,58$ & $-1,48^{*}$ & $-1,52$ & $-2,67$ & $-2,67$ & $-1,93$ & $-1,12$ & 0,44 & $-0,63$ & $-2,52$ \\
\hline Teste T & 0,07 & $-1,72$ & $-2,47$ & $-0,99$ & $-1,54$ & $-1,09$ & $-0,6$ & $-0,3$ & 0,09 & $-0,13$ & $-0,69$ \\
\hline Retorno Anormal 2 & 0,15 & $-1,56^{*}$ & $-0,22$ & 0,62 & $-1,16$ & 0,13 & 0,58 & 0,8 & 1,34 & $-1,14$ & $-1,11$ \\
\hline Teste T & 0,18 & $-2,66$ & $-1,18$ & 1,04 & $-1,73$ & 0,12 & 0,69 & 1,19 & 0,76 & $-0,96$ & $-0,57$ \\
\hline$\%$ RA $2 \geq 0$ & 0,8 & 0,2 & 0,4 & 0,8 & 0,4 & 0,8 & 0,8 & 0,8 & 0,6 & 0,6 & 0,4 \\
\hline CAR 2 & 0,15 & $-1,42$ & $-1,64 *$ & $-1,02$ & $-2,19$ & $-2,05$ & $-1,47$ & $-0,67$ & 0,67 & $-0,47$ & $-1,58$ \\
\hline Teste T & 0,18 & $-2,11$ & $-2,46$ & $-0,98$ & $-1,48$ & $-0,85$ & $-0,46$ & $-0,18$ & 0,13 & $-0,08$ & $-0,36$ \\
\hline \multicolumn{12}{|c|}{ Painel C - Diferenças de médias - Retorno anormal cumulativo durante os dias $-2 \mathrm{e} 0$} \\
\hline Data & Entrada & Saída & T-Teste & & & & & & & & \\
\hline CAR1 & 3,96 & $-1,2$ & 0,84 & & & & & & & & \\
\hline CAR2 & 2,99 & 0,41 & 0,61 & & & & & & & & \\
\hline
\end{tabular}
2,99 
Alterações ao IBrX50

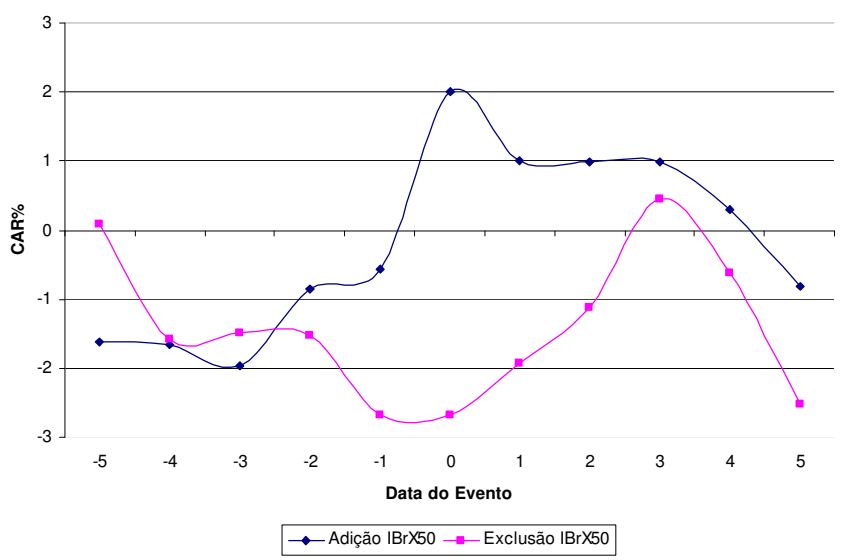

Figura 2

Retorno Anormal Cumulativo - Alterações no IBrX50

A figura apresenta uma evolução dos retornos anormais cumulativos durante a janela do evento para a amostra de alterações no IBrX50.

A Tabela 6 - Painel A apresenta os resultados para as ações adicionadas ao IBrX100. Ao contrário dos resultados anteriores, não existe evidência de retornos anormais expressivos durante a janela do evento. Por exemplo, quando utilizado o modelo de mercado, documentou-se retornos anormais de $-0,61 \%$ na data “-2" e $-0,57 \%$ na data " 1 " com retornos menores nos demais dias. Os resultados para as ações excluídas do índice (Tabela 6 - Painel B) apresentam um retorno anormal negativo de $-1,51 \%$ e $-1,29 \%$ na data do evento dependendo do modelo para o cálculo dos retornos anormais. O Painel $\mathrm{C}$ apresenta o teste de diferenças de médias para o retorno anormal cumulativo das datas "-2" até "0". Neste caso, existe evidência marginalmente significativa de que os retornos anormais são mais negativos para empresas excluídas do IBrX100 do que empresas adicionadas ao índice.

A Figura 3 sumariza o comportamento das ações durante a janela do evento. Ao contrário dos resultados anteriores, não existe evidência de retornos anormais positivos em torno da data do evento. De fato, observa-se uma tendência negativa nos preços das ações adicionadas ao IBrX100 persistente até o final da janela do evento. No entanto, para os eventos de exclusão do IBrX100, documenta-se um retorno anormal cumulativo negativo e estável após a data do evento. 
Tabela 6

Retornos Anormais Percentuais para as Alterações no IBrX100

A tabela apresenta os retornos anormais diários e retornos anormais cumulativos para cada dia da janela do evento para a amostra de alterações no IBrX100. A tabela também apresenta estatísticas descritivas e testes de significâncias para os retornos anormais diários. O Painel C apresenta o teste de diferença de médias para os retorno anormal cumulativo durante as data -2 a $0 . * * *, * *, *$ : Níveis de significância de $1 \%, 5 \%$ e $10 \%$ respectivamente.

\begin{tabular}{|c|c|c|c|c|c|c|c|c|c|c|c|}
\hline Data & $\frac{11}{-5}$ & -4 & -3 & -2 & -1 & 0 & 1 & 2 & 3 & 4 & 5 \\
\hline Retorno Anormal 1 & $-0,19$ & $-0,36$ & $-0,4$ & $-0,61 * *$ & 0,17 & $-0,35$ & $-0,57^{* *}$ & $-0,17$ & $-0,3$ & 0 & $-0,64 * *$ \\
\hline Teste T & $-0,66$ & $-1,4$ & $-1,6$ & $-2,36$ & 0,6 & $-0,99$ & $-2,17$ & $-0,64$ & $-1,09$ & 0 & $-2,46$ \\
\hline$\%$ RA $1 \geq 0$ & 0,48 & 0,42 & 0,45 & 0,42 & 0,48 & 0,47 & 0,42 & 0,45 & 0,43 & 0,45 & 0,43 \\
\hline CAR 1 & $-0,19$ & $-0,55$ & $-0,95 * *$ & $-1,56 * * *$ & $-1,39 * *$ & $-1,74 * *$ & $-2,31^{* * *}$ & $-2,48 * * *$ & $-2,78^{* * * *}$ & $-2,78^{* * * *}$ & $-3,42 * * *$ \\
\hline Teste T & $-0,66$ & $-1,4$ & $-2,24$ & $-3,04$ & $-2,37$ & $-2,49$ & $-3,21$ & $-3,35$ & $-3,52$ & $-3,53$ & $-4,01$ \\
\hline Retorno Anormal 2 & $-0,52^{*}$ & $-0,09$ & $-0,39$ & $-0,34$ & 0,46 & $-0,70^{*}$ & $-0,53 *$ & $-0,05$ & $-0,2$ & 0,33 & $-0,18$ \\
\hline Teste T & $-1,88$ & $-0,32$ & $-1,51$ & $-1,3$ & 1,57 & $-1,83$ & $-1,74$ & $-0,17$ & $-0,71$ & 1,04 & $-0,56$ \\
\hline$\%$ RA $2 \geq 0$ & 0,44 & 0,5 & 0,45 & 0,47 & 0,5 & 0,43 & 0,42 & 0,5 & 0,48 & 0,51 & 0,5 \\
\hline CAR 2 & $-0,52$ & $-0,61$ & $-1,00 * *$ & $-1,34 * *$ & $-0,87$ & $-1,57^{* *}$ & $-2,10^{* * *}$ & $-2,15 * * *$ & $-2,35 * * *$ & $-2,02 * *$ & $-2,20 * *$ \\
\hline Teste T & $-1,88$ & $-1,5$ & $-2,22$ & $-2,49$ & $-1,45$ & $-2,11$ & $-2,82$ & $-2,67$ & $-2,71$ & $-2,26$ & $-2,2$ \\
\hline \multicolumn{12}{|c|}{ Painel B - Exclusões no IBrX100 } \\
\hline Data & -5 & -4 & -3 & -2 & -1 & 0 & 1 & 2 & 3 & 4 & 5 \\
\hline Retorno Anormal 1 & $-0,59$ & 0,37 & $-0,14$ & $-0,3$ & $-0,54$ & $-1,51^{\text {**** }}$ & 0,05 & $-0,46$ & 0,15 & $-0,19$ & 0,26 \\
\hline Teste T & $-1,71$ & 0,95 & $-0,46$ & $-0,89$ & $-1,3$ & $-3,12$ & 0,13 & $-1,37$ & 0,47 & $-0,57$ & 0,67 \\
\hline$\%$ RA $1 \geq 0$ & 0,36 & 0,55 & 0,34 & 0,45 & 0,49 & 0,32 & 0,47 & 0,42 & 0,45 & 0,53 & 0,47 \\
\hline CAR 1 & $-0,59 *$ & $-0,22$ & $-0,36$ & $-0,66$ & $-1,2$ & $-2,70^{* * * *}$ & $-2,65 * *$ & $-3,12^{* * *}$ & $-2,96 * * * *$ & $-3,15^{* * * *}$ & $-2,90 * *$ \\
\hline Teste T & $-1,71$ & $-0,41$ & $-0,6$ & $-0,95$ & $-1,53$ & $-2,72$ & $-2,59$ & $-3,12$ & $-2,91$ & $-3,05$ & $-2,5$ \\
\hline Retorno Anormal 2 & $-0,31$ & 0,33 & 0,06 & $-0,29$ & $-0,59$ & $-1,29 * *$ & 0,05 & $-0,27$ & 0,17 & $-0,25$ & $-0,02$ \\
\hline Teste T & $-0,86$ & 0,8 & 0,19 & $-0,79$ & $-1,35$ & $-2,39$ & 0,11 & $-0,81$ & 0,49 & $-0,73$ & $-0,04$ \\
\hline$\%$ RA2 $\geq 0$ & 0,49 & 0,55 & 0,36 & 0,47 & 0,48 & 0,39 & 0,48 & 0,46 & 0,43 & 0,54 & 0,5 \\
\hline CAR 2 & $-0,31$ & 0,02 & 0,08 & $-0,21$ & $-0,8$ & $-2,08^{*}$ & $-2,04 *$ & $-2,30^{*}$ & $-2,14$ & $-2,39 *$ & $-2,41$ \\
\hline Teste T & $-0,86$ & 0,04 & 0,13 & $-0,26$ & $-0,87$ & $-1,77$ & $-1,72$ & $-1,93$ & $-1,66$ & $-1,8$ & $-1,63$ \\
\hline \multicolumn{12}{|c|}{ Painel C - Diferenças de médias - Retorno anormal cumulativo durante os dias $-2 \mathrm{e} 0$} \\
\hline Data & Entrada & Saída & T-Teste & & & & & & & & \\
\hline CAR1 & $-0,78$ & $-2,35$ & $1,79^{*}$ & & & & & & & & \\
\hline CAR2 & $-0,58$ & $-2,17$ & 1,65 & & & & & & & & \\
\hline
\end{tabular}




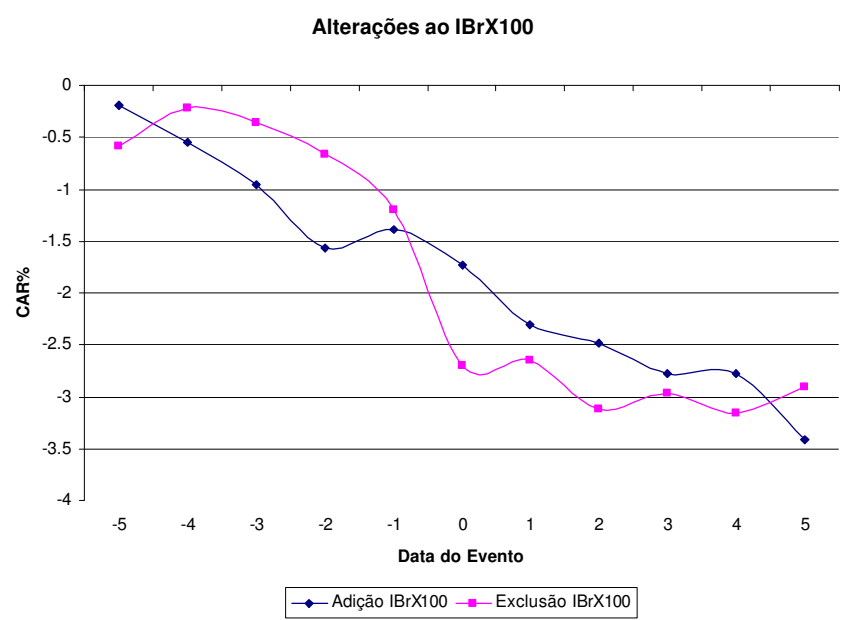

Figura 3

Retorno Anormal Cumulativo - Alterações no IBrX100

A figura apresenta uma evolução dos retornos anormais cumulativos durante a janela do evento para a amostra de alterações no IBrX100.

Finalmente, a Tabela 7 - Painel A apresenta os resultados para as ações adicionadas ao índice FGV100. Neste caso, observa-se uma estabilidade nos retornos das ações adicionadas ao índice e com baixa significância estatística. O mesmo ocorre com as ações excluídas do índice (Painel B) onde se evidencia uma queda nos preços das ações antes da data do evento que tende a ser revertido ao final da janela. O Painel C apresenta o teste de diferenças de médias para o retorno anormal cumulativo das datas "-2" até " 0 ". Assim como no IBrX50, não encontrou-se diferenças significativa entre os retornos anormais cumulativos das ações adicionadas e excluídas ao índice FGV100. A Figura 4 sumariza o comportamento das ações durante a janela do evento. 
Alterações ao FGV100

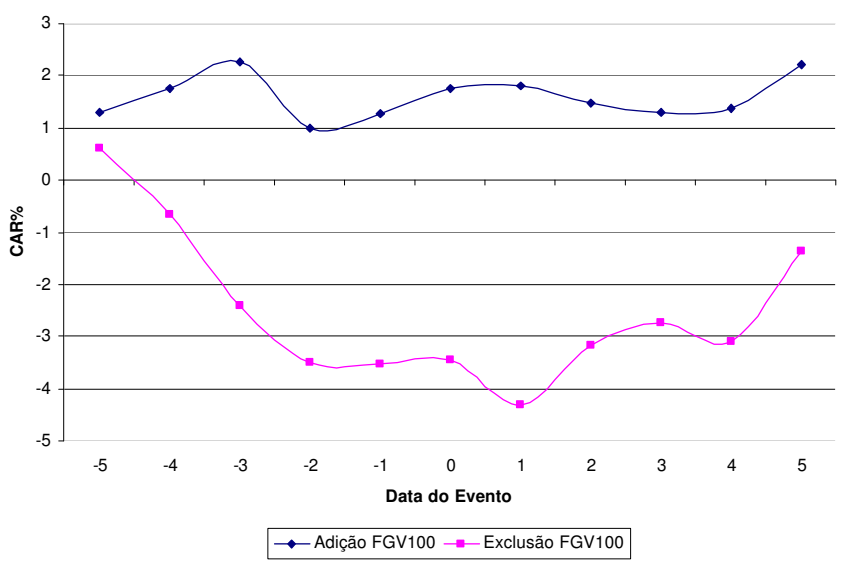

Figura 4

Retorno Anormal Cumulativo - Alterações no Índice FGV100

A figura apresenta uma evolução dos retornos anormais cumulativos durante a janela do evento para a amostra de alterações no ìndice FGV100.

Em geral, os resultados dos retornos anormais nos permitem chegar a algumas conclusões. Não existe evidência de retornos anormais em torno do anúncio da prévia da alteração do IBOVESPA. Em torno da data da efetivação, encontrou-se uma reação positiva na data do evento para as adições no IBOVESPA e no IBrX50 mas esse efeito torna-se negativo ao final da janela do evento de cinco dias. O único caso de retornos anormais cumulativos positivos ao final da janela do evento de cinco dias foi em torno das empresas adicionadas ao índice FGV100, porém esse resultado não é significativo estatisticamente. Já no caso das exclusões, em todos os casos constatou-se evidência de retornos anormais cumulativos negativos. No entanto, observou-se significância estatística apenas para exclusões no IBOVESPA e no IBrX100. 
Tabela 7

A tabela apresenta os retornos anormais diários e retornos anormais cumulativos para cada dia da janela do evento para a amostra de alterações no índice FGV100. A tabela também apresenta estatísticas descritivas e testes de significâncias para os retornos anormais

\begin{tabular}{|c|c|c|c|c|c|c|c|c|c|c|c|}
\hline Data & -5 & -4 & -3 & -2 & -1 & 0 & 1 & 2 & 3 & 4 & 5 \\
\hline Retorno Anormal 1 & $1,29^{* *}$ & 0,48 & 0,51 & $-1,28^{* * *}$ & 0,27 & 0,49 & 0,06 & $-0,32$ & $-0,2$ & 0,09 & $0,83^{*}$ \\
\hline Teste T & 2,45 & 0,8 & 1,08 & $-2,26$ & 0,51 & 1,02 & 0,1 & $-0,69$ & $-0,46$ & 0,17 & 1,7 \\
\hline$\%$ RA $1 \geq 0$ & 0,65 & 0,67 & 0,47 & 0,43 & 0,45 & 0,55 & 0,57 & 0,43 & 0,53 & 0,47 & 0,55 \\
\hline CAR 1 & $1,29^{* * *}$ & $1,77^{* *}$ & $2,28 * * *$ & 0,99 & 1,26 & $1,75^{*}$ & 1,81 & 1,49 & 1,29 & 1,38 & 2,2 \\
\hline Teste $\mathrm{T}$ & 2,45 & 2,67 & 3,05 & 1,22 & 1,35 & 1,8 & 1,65 & 1,41 & 1,13 & 1,13 & 1,63 \\
\hline Retorno Anormal 2 & $1,39^{* *}$ & 0,3 & 0,17 & $-1,43^{* *}$ & 0,44 & 0,77 & 0,41 & 0,09 & 0,14 & 0,38 & $1,07^{*}$ \\
\hline Teste T & 2,21 & 0,5 & 0,3 & $-2,09$ & 0,78 & 1,39 & 0,66 & 0,16 & 0,27 & 0,6 & 1,82 \\
\hline$\%$ RA2 $\geq 0$ & 0,57 & 0,63 & 0,47 & 0,35 & 0,51 & 0,53 & 0,57 & 0,47 & 0,51 & 0,55 & 0,59 \\
\hline CAR 2 & $1,39^{* * *}$ & $1,70^{* *}$ & $1,87^{*}$ & 0,43 & 0,87 & 1,64 & 2,05 & 2,14 & 2,28 & 2,66 & $3,73^{*}$ \\
\hline Teste T & 2,21 & 2,16 & 1,91 & 0,38 & 0,66 & 1,21 & 1,28 & 1,27 & 1,26 & 1,33 & 1,73 \\
\hline \multicolumn{12}{|c|}{ Painel B - Exclusões ao Índice FGV100 } \\
\hline Data & -5 & -4 & -3 & -2 & -1 & 0 & 1 & 2 & 3 & 4 & 5 \\
\hline Retorno Anormal 1 & 0,6 & $-1,26$ & $-1,75$ & $-1,1$ & $-0,02$ & 0,07 & $-0,86$ & 1,15 & 0,41 & $-0,34$ & $1,73^{*}$ \\
\hline Teste $\mathrm{T}$ & 0,5 & $-1,22$ & $-1,48$ & $-1,27$ & $-0,01$ & 0,06 & $-0,81$ & 1,28 & 0,73 & $-0,42$ & 1,83 \\
\hline$\%$ RA $1 \geq 0$ & 0,64 & 0,5 & 0,32 & 0,23 & 0,45 & 0,45 & 0,41 & 0,64 & 0,64 & 0,45 & 0,55 \\
\hline CAR 1 & 0,6 & $-0,66$ & $-2,4$ & $-3,5$ & $-3,52$ & $-3,45$ & $-4,31 *$ & $-3,16$ & $-2,75$ & $-3,09$ & $-1,36$ \\
\hline Teste & 0,5 & $-0,43$ & $-1,14$ & $-1,49$ & $-1,54$ & $-1,5$ & $-1,75$ & $-1,31$ & $-1,27$ & $-1,39$ & $-0,57$ \\
\hline Retorno Anormal 2 & $-1,03$ & $-2,31$ & $-1,85$ & $-1,26$ & $-0,34$ & 1,09 & 1,46 & $-0,7$ & 0,89 & 1,21 & 0,87 \\
\hline Teste $\mathrm{T}$ & $-0,91$ & $-1,58$ & -1 & $-1,09$ & $-0,42$ & 1,35 & 1,12 & $-0,71$ & 1,08 & 0,94 & 1,22 \\
\hline$\%$ RA2 $\geq 0$ & 0,5 & 0,36 & 0,36 & 0,36 & 0,36 & 0,64 & 0,5 & 0,43 & 0,71 & 0,5 & 0,71 \\
\hline CAR $2-$ & $-1,03$ & $-3,34$ & $-5,2$ & $-6,46^{*}$ & $-6,80^{*}$ & $-5,71$ & $-4,25$ & $-4,95$ & $-4,06$ & $-2,85$ & $-1,98$ \\
\hline Teste T & $-0,91$ & $-1,7$ & $-1,7$ & $-1,96$ & $-2,15$ & $-1,71$ & $-1,25$ & $-1,35$ & $-1,16$ & $-0,71$ & $-0,45$ \\
\hline \multicolumn{12}{|c|}{ Painel C - Diferenças de médias - Retorno anormal cumulativo durante os dias $-2 \mathrm{e} 0$} \\
\hline Data & Entrada & Saída & T-Teste & & & & & & & & \\
\hline CAR & $-0,5$ & $-1,0$ & & & & & & & & & \\
\hline CAR2 & $-0,22$ & $-0,51$ & 0,15 & & & & & & & & \\
\hline
\end{tabular}




\subsection{Estudo de evento - volumes anormais}

Conforme discutido na Seção 2, realizou-se também uma análise do volume das ações negociadas para cada caso em que houve a adição ou exclusão ao IBOVESPA. A Tabela 8 - Painel A apresenta os volumes anormais médios diários para as ações adicionadas ao índice. Conforme estudos semelhantes nos Estados Unidos, encontraram-se volumes anormais positivos de $31 \%$ na data “-2”, $75 \%$ na data “-1" e $32 \%$ na data da alteração das carteiras, significativos ao nível de 5\%. Os volumes anormais nas demais datas são menos expressivos. Da mesma forma, o Painel B apresenta os volumes anormais médios diários para as ações excluídas do IBOVESPA. Neste caso, encontraram-se volumes anormais de $43 \%$ na data "-1" e volumes anormais negativos na maioria da janela do evento. A Figura 5 sumariza os volumes de negociação durante a janela do evento. Em geral, constata-se a existência de volumes anormais nos dias anteriores a alteração da carteira para ações adicionadas e excluídas ao índice. Os resultados podem ser interpretados como um ajuste na composição da carteira de fundos de investimentos que tem como objetivo replicar a rentabilidade do IBOVESPA. 
Tabela 8

Volumes Anormais Percentuais para as Alteraç̃̃es no IBOVESPA

A tabela apresenta os volumes anormais diários, estatísticas descritivas e testes de significâncias pra cada dia da janela do evento para A a

\begin{tabular}{|c|c|c|c|c|c|c|c|c|c|c|c|}
\hline Data & -5 & -4 & -3 & -2 & -1 & 0 & 1 & 2 & 3 & 4 & 5 \\
\hline Média & $-0,18^{\text {*** }}$ & $-0,11$ & $-0,1$ & $0,31^{* *}$ & $0,75^{* * * *}$ & 0,32 ** & $-0,09$ & $-0,12^{*}$ & $-0,22^{* * * *}$ & $-0,24 * * *$ & $-0,15^{*}$ \\
\hline Desvio Padrão & 0,58 & 0,6 & 0,49 & 0,96 & 1,34 & 0,95 & 0,61 & 0,47 & 0,42 & 0,5 & 0,57 \\
\hline Mediana & 1,24 & 1,66 & 1,33 & 3,32 & 3,35 & 3,35 & 1,7 & 0,94 & 0,94 & 1,34 & 1,15 \\
\hline Maior Valor & $-0,33$ & $-0,32$ & $-0,18$ & 0,08 & 0,41 & 0,32 & $-0,15$ & $-0,15$ & $-0,26$ & $-0,39$ & $-0,28$ \\
\hline Menor Valor & $-0,96$ & $-0,95$ & $-0,77$ & $-0,89$ & $-0,89$ & $-0,93$ & $-0,95$ & $-0,82$ & $-0,96$ & $-0,8$ & $-0,92$ \\
\hline Eventos & 44 & 44 & 44 & 44 & 44 & 44 & 44 & 44 & 44 & 44 & 44 \\
\hline Teste T & $-2,09$ & $-1,19$ & $-1,42$ & 2,18 & 3,71 & 2,21 & -1 & $-1,67$ & $-3,53$ & $-3,17$ & $-1,77$ \\
\hline \multicolumn{12}{|c|}{ Painel B - Exclusões no IBOVESPA } \\
\hline Data & -5 & -4 & -3 & -2 & -1 & 0 & 1 & 2 & 3 & 4 & 5 \\
\hline Média & $-0,42^{* * * *}$ & $-0,23$ & $-0,14$ & $-0,05$ & $0,43^{* *}$ & 0,04 & $-0,22^{* *}$ & $-0,37^{* * * * *}$ & $-0,17$ & 0,06 & $-0,2$ \\
\hline Desvio Padrão & 0,65 & 0,86 & 1,02 & 0,71 & 1,15 & 1,1 & 0,67 & 0,57 & 0,89 & 1,11 & 0,81 \\
\hline Mediana & 1,37 & 2,58 & 2,78 & 2 & 2,71 & 3,35 & 1,55 & 1 & 2,34 & 3,35 & 2,4 \\
\hline Maior Valor & $-0,67$ & $-0,48$ & $-0,58$ & $-0,21$ & 0,1 & $-0,25$ & $-0,38$ & $-0,46$ & $-0,35$ & $-0,43$ & $-0,51$ \\
\hline Menor Valor & -1 & -1 & -1 & $-0,96$ & -1 & -1 & -1 & -1 & -1 & -1 & -1 \\
\hline Eventos & 37 & 37 & 37 & 37 & 37 & 37 & 37 & 37 & 37 & 37 & 37 \\
\hline Teste $\mathrm{T}$ & $-3,91$ & $-1,65$ & $-0,82$ & $-0,45$ & 2,27 & 0,23 & $-1,99$ & $-3,91$ & $-1,19$ & 0,33 & $-1,49$ \\
\hline
\end{tabular}


Alterações ao IBOVESPA

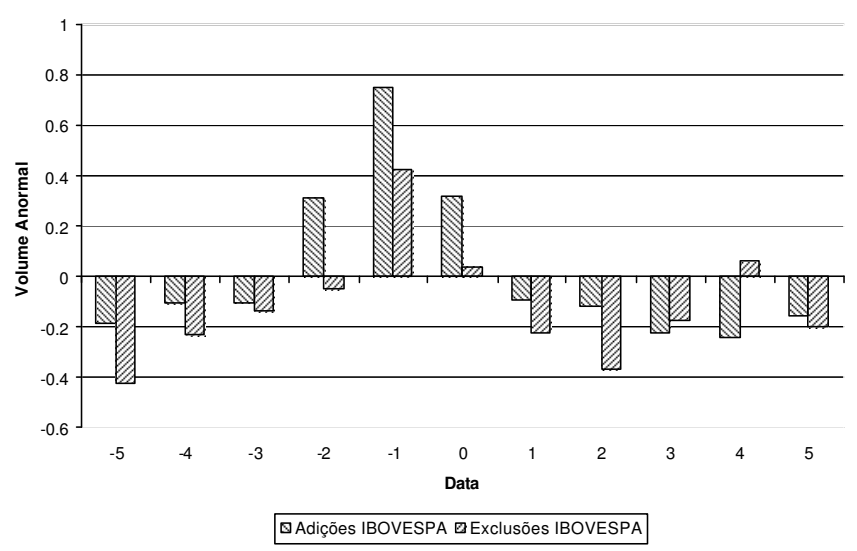

Figura 5

Volumes Anormais - Alterações no IBOVESPA

A figura apresenta os volumes anormais diários durante a janela do evento para a amostra de alterações no IBOVESPA.

\section{Considerações Finais}

Diversas teorias tentam explicar o efeito no preço das ações adicionadas ou excluídas aos índices financeiros. Tradicionalmente, a teoria financeira assume que a adição ou exclusão de uma ação a um índice financeiro não deveria afetar o preço da respectiva ação. Outros estudos sugerem que a reação do mercado pode refletir uma mudança na percepção dos investidores em relação ao fluxo de caixa esperado ou ao custo de capital. Finalmente, alguns estudos questionam o pressuposto de que a demanda das ações em relação ao preço é perfeitamente elástica. Neste caso, a explicação para o movimento no preço das ações deve-se ao fato de que a curva de demanda é decrescente e, portanto o preço da ação é afetado por uma demanda anormal por este ativo.

Esse estudo contribui para essa literatura através de uma avaliação do comportamento do preço e do volume das negociações de ações adicionadas e excluídas no IBOVESPA, no IBrX50 e no IBrX100 durante os anos 1994 a 2002 e no índice FGV100 durante os anos 2000 a 2002. Um fator diferenciador desse estudo no mercado brasileiro é que a BOVESPA apresenta a prévia da alteração do IBOVESPA com 30 dias de antecedência da data efetiva. Isso permite separar o efeito informacional do efeito de liquidez devido a ajustes de carteiras dos fundos indexados a estes índices. Além disso, a BOVESPA estabelece critérios definidos para alterações na carteira do IBOVESPA. Neste caso é possível que os investidores antecipem a alteração da carteira e a data da prévia não tenha valor informacional. 
Os resultados sugerem que não existe evidência de retornos anormais em torno da prévia das alterações do IBOVESPA em contraste com resultados obtidos nos Estados Unidos. Uma possível explicação para o fato é que, devido a BOVESPA adotar critérios definidos para a inclusão e exclusão de uma companhia na carteira, é possível que os investidores antecipem a alteração da composição do IBOVESPA o que torna a data da prévia da BOVESPA não informativa.

A análise de retornos anormais em torno da data da efetiva alteração da carteira sugere uma reação positiva para ações incluídas no IBOVESPA e no IBrX50 em torno da data do evento porém esse efeito torna-se negativo ao final da janela do evento de cinco dias. Já no caso das exclusões, em todos os casos constatou-se evidência de retornos anormais cumulativos negativos ao final de cinco dias após a efetiva alteração das carteiras. Esses resultados sugerem que a elasticidade da demanda em relação ao preço das empresas adicionadas ou excluídas aos índices brasileiros não é perfeitamente elástica uma vez que se observaram retornos anormais temporários em torno da data do evento. Finalmente, constata-se a existência de volumes anormais nos dias anteriores a alteração da carteira para ações adicionadas e excluídas no IBOVESPA. Os resultados podem ser interpretados por um ajuste na composição da carteira de fundos de investimentos que tem como objetivo replicar a rentabilidade do IBOVESPA.

\section{Referências}

Beneish, M. D. \& Whaley, R. E. (1996). An anatomy of the 'S\&P 500 Game': The effects of changing the rules. Journal of Finance, 51:1909-1930.

Blouin, J., Raedy, J., \& Shackelford, D. (2000). The impact of capital gains taxes on stock price reactions to S\&P 500 inclusion. NBER Working Paper 8011.

Brown, S. \& Warner, J. (1980). Measuring security price performance. Journal of Financial Economics, 8(3):205-58.

Brown, S. \& Warner, J. (1985). Using daily stocks returns: The case of event studies. Journal of Financial Economics, 14(4):3-31.

Chen, H., Noronha, G., \& Singal, V. (2004). The price response to S\&P 500 index additions and deletions: Evidence of asymmetry and a new explanation. Journal of Finance, 59(4):1901-1929.

Chordia, T. (2001). The impact of inclusion into the S\&P 500 index. Working Paper Emory University.

Denis, D., McConnell, J., Ovtchinnikov, A., \& Yu, Y. (2003). S\&P 500 index additions and earnings expectations. Journal of Finance, 58:1821-1840.

Dhillon, U. \& Johnson, H. (1991). Changes in the standard and poor's 500 list. Journal of Business, 64(1):75-86. 
Elliot, W. \& Warr, R. (2003). Price pressure on NYSE and NASDAQ: Evidence from S\&P 500 index changes. Financial Management, 32:85-99.

Goetzmann, W. \& Garry, M. (1986). Does delisting from the S\&P 500 affect stock price? Financial Analyst Journal, 42:64-69.

Harris, L. \& Eitan, G. (1986). Price and volume effects associated with changes in the S\&P 500 list: New evidence for the existence of price pressure. The Journal of Finance, 41(4):815-829.

Hegde, S. \& McDermott, J. (2003). The liquidity effects of revisions to the S\&P 500 index: An empirical analysis. Journal of Financial Markets, 6:413-459.

Jain, P. C. (1987). The effect on stock price of inclusion in or exclusion from the S\&P 500. Financial Analyst Journal, 43(1):58-65.

Kaul, A., Mehrotra, V., \& Morck, R. (2000). Demand curves for stocks to slope down: New evidence from an index weights adjustment. Journal of Finance, 55:893-912.

Kloeckner, G. O. (1995). Estudos de eventos: A análise de um método. Revista Brasileira de Administração Contemporânea, 1(2):261-270.

Liu, S. (2001). Changes in the Nikkei 500: New evidence for downward-sloping demand curves for stocks. SSRN working paper.

Lynch, A. \& Mendenhall, R. (1997). New evidence on stock price effects associated with changes in the S\&P 500 index. The Journal of Business, 70(3):351-383.

Mackinlay, C. (1997). Event studies in economics and finance. Journal of Economic Literature, 35:13-39.

Merton, R. (1987). A simple model of capital market equilibrium with incomplete information. Journal of Finance, 42:483-510.

Modigliani, F. \& Miller, M. (1958). The cost of capital, corporation finance and the theory of investment. American Economic Review, 48(3):261-297.

Salazar, J. N. (1997). Avaliação empírica do comportamento das ações no contexto da reavaliação da carteria teórica do índice IBOVESPA. Tese de doutorado em Administração de Empresas. Fundação Getulio Vargas - SP, Brasil.

Shleifer, A. (1986). Do demand curves for stocks slope down. The Journal of Finance, 41(3):579-590. 